\title{
Improvement of Corrosion Resistance and Adhesion of Coating Layer for Magnesium Alloy Coated with High Purity Magnesium
}

\author{
Shinji Fukumoto, Kana Sugahara*, Atsushi Yamamoto and Harushige Tsubakino \\ Graduate School of Engineering, Himeji Institute of Technology, Himeji 671-2201, Japan
}

AZ31 magnesium alloy was coated with high purity magnesium by vapor deposition coating process at high temperature in order to improve the corrosion resistance. Interdiffusion of each element was observed at the interface during the deposition coating process. The high purity magnesium coating showed superior corrosion resistance in salt solution. Although corrosion resistance was improved dramatically by the vapor deposition coating process, there were a lot of voids and pin-holes at the interface and in the coating layer, respectively. Hot press and HIP processes were carried out to decrease the voids and pin-holes. They were disappeared completely by hot press and HIP processes, resulting in improvement of adhesion property. Moreover, corrosion resistance was also improved due to disappearance of voids and pin-holes. Besides, the high purity magnesium coating worked as sacrificial anode in the cross cut test, resulting in protecting the substrate.

(Received October 21, 2002; Accepted December 5, 2002)

Keywords: deposition coating, magnesium alloy, corrosion resistance, hot press, adhesion, diffusion bonding

\section{Introduction}

Due to the increasing environmental regulation, automakers and consumer electronics makers are looking for new materials that are light and easy to recycle. Magnesium alloys are attractive due to their superior properties such as high specific strength and recyclability that is almost equal to that of aluminum. So they are used for mobile phone, laptop computer, camera, automotive components and so on. But it is well known that their corrosion resistance is very poor in comparison with other practical alloys. Therefore, some kind of surface modification is necessary to use magnesium alloys in severe environment for long term. Their corrosion resistance could be improved by not only conventional ones such as plating, anodizing and chemical conversion treatment ${ }^{1-3)}$ but laser cladding ${ }^{4)}$ and magnetron co-sputtering deposition. ${ }^{5)}$

Meanwhile, Hanawalt et al. reported that corrosion resistance of magnesium depended on amount of impurity, especially heavy metals such as iron, chromium, nickel and cobalt. ${ }^{6)}$ They investigated the effects of impurities and found the existence of well-defined tolerance limits below which the presence of these elements had little effect on the corrosion resistance of magnesium. Moreover, Takaya et al. reported high purity $6 \mathrm{~N}$-grade pure magnesium showed much better corrosion resistance in simulated body fluid than commercial purity pure magnesium. ${ }^{7)}$ Solution potential of magnesium in dilute chloride solutions is quite less than that of the other metals. Consequently the corrosion behavior of magnesium in electrolytes is likely to be dominated by galvanic effects, when magnesium is directly coupled with a dissimilar metal. ${ }^{8)}$ This is the reason why high purity magnesium has superior corrosion resistance.

Therefore, surface layers which are coated by conventional methods as mentioned above will be impurity in molten magnesium when magnesium products are melted for their recycling. It is necessary to remove the coating layers before recycling process to obtain high quality secondary magne-

*Graduate Student, Himeji Institute of Technology. sium alloy. These conventional coating processes are undesirable for recycling magnesium alloys. In the point of view, although ion implantation ${ }^{9,10)}$ is better than the conventional treatments, thickness and area of improved layer are extreme thin and small, respectively.

So a new surface modification method which was easy to cover whole product with high purity magnesium and not expensive was developed by the authors. ${ }^{11,12)}$ Corrosion resistance of AZ31 magnesium alloy could be improved by the deposition coating process. On the other hand, it is well known that it is difficult to obtain high adhesive strength between coating layer and the substrate via deposition coating process. So it is necessary to improve the adhesion after the vapor deposition.

In this study, the vacuum vapor deposition was performed to improve the corrosion resistance of magnesium alloy. Furthermore the improvement of adhesion between coating layer and magnesium alloy substrate by hot press and HIP (hot isostatic pressing) was investigated.

\section{Experimental Procedures}

Commercial grade pure magnesium with three nine purity (3N-grade) and magnesium alloy AZ31 were used as a substrate and an evaporation source, respectively. The chemical compositions are shown in Table 1. AZ91 and high purity magnesium of six nine grade $(6 \mathrm{~N})$ were also used for corrosion test. The size of substrate was cut out into $10 \times 10 \times 6 \mathrm{~mm}^{3}$. Surfaces of the substrate AZ31 were mechanically polished with emery paper and finished at \#2000. Deposition coating was carried out in the horizontal vacuum furnace that has five heating zones. Evaporation source of $3 \mathrm{~N}-\mathrm{Mg}$ and the substrate AZ31 were kept at $955 \mathrm{~K}$ and $629 \mathrm{~K}$ for $7.2 \mathrm{ks}$ under $3 \times 10^{-3} \mathrm{~Pa}$ in vacuum. Further details on the coating procedure were reported in the other literatures. ${ }^{11)}$

After the deposition coating, the hot press and HIP were carried out on the coated specimen in order to improve the adhesion between coating layer and substrate. The AZ31 with deposition coating was kept under the uni-axial pressure at 
Table 1 Chemical composition of materials (mass\%).

\begin{tabular}{|c|c|c|c|c|c|c|c|}
\hline & $\mathrm{Al}$ & $\mathrm{Zn}$ & $\mathrm{Mn}$ & $\mathrm{Si}$ & $\mathrm{Cu}$ & $\mathrm{Ni}$ & $\mathrm{Fe}$ \\
\hline $3 \mathrm{~N}-\mathrm{Mg}$ & 0.004 & 0.003 & 0.004 & 0.005 & $<0.001$ & $<0.001$ & 0.002 \\
\hline AZ31 & 2.51 & 0.84 & 0.003 & 0.003 & 0.001 & - & 0.004 \\
\hline AZ91E & 8.1 & 0.6 & 0.25 & 0.03 & 0.003 & $<0.001$ & 0.003 \\
\hline $6 \mathrm{~N}-\mathrm{Mg}$ & 0.000001 & - & 0.000005 & 0.000016 & $<0.000005$ & $<0.00001$ & 0.000002 \\
\hline
\end{tabular}

$673 \mathrm{~K}$ and $523 \mathrm{~K}$ in argon atmosphere and air, respectively. The uni-axial load were varied from 0 to $50 \mathrm{MPa}$. The holding time are $3.6 \mathrm{ks}$ and $7.2 \mathrm{ks}$. HIP was also carried out in the aluminum capsule under the condition of $673 \mathrm{~K}, 7.2 \mathrm{ks}$ and $100 \mathrm{MPa}$.

Adhesion between substrate and coating layer was evaluated by bending and peel tests. The specimen for the bending test was cut out of coated AZ31 into $10 \times 3 \times 0.5 \mathrm{~mm}^{3}$. Stud pin was bonded onto the deposition coating with epoxy resin and it was pulled off to estimate the adhesion by tensile testing machine. The interface and surface of coating layer were observed after bending test by scanning electron microscope (SEM).

The cross sections of coated specimens were observed by optical microscope. The element concentration near the interface between substrate and coating layer was measured by EPMA (electron probe X-ray microanalyzer). Corrosion resistance of the specimens was evaluated through immersion and cross cut tests in $3 \% \mathrm{NaCl}$ solution at $300 \mathrm{~K}$.

\section{Results and Discussion}

\subsection{Deposition coating process}

Figure 1 shows the cross sections with and without etching of deposition coated AZ31 alloy. The deposition layer grew up epitaxially from the substrate and the thickness was approximately $65 \mu \mathrm{m}$. The deposition rate was approximately $1.4 \times 10^{-3} \mathrm{mg} / \mathrm{s}(9 \mathrm{~nm} / \mathrm{s})$ and the magnesium was deposited homogeneously on whole surface of substrate. Generally, it is difficult to make a coating without void and pin-hole by conventional deposition coating process. In this work, a lot of voids and pin-holes were formed at the interface and coating layer, respectively, too. The void ratio which total length of each void was divided by length of the interface in a cross section was approximately $25 \%$. Although substrate had equiaxed structure of several tens $\mu \mathrm{m}$ in grain size, a lot of small grains of several $\mu \mathrm{m}$ were observed near the boundary. Since the surface of substrate was polished by emery paper before deposition coating, the strain was introduced at the surface region. As a result, the recrystallization occurred during the deposition coating process, resulting in the formation of small grains on the surface.

The distribution of each element was measured by EMPA and the result is shown in Fig. 2. In general, the adhesion between deposition layer and substrate is poor since the conventional deposition process is carried out at room temperature. On the other hand, since the deposition process in the present work is carried out at high temperature, the adhesion will be improved in comparison with the regular deposition process. Slight concentration gradient was detected at the interface between coating layer and the substrate. The concentration gradient at the interface is estimated by diffusion model as follows. The diffusion of magnesium in magnesium is calculated by the solution for a pair of semiinfinite solid is given by eq. (1), ${ }^{13)}$

$$
c(x, t)=C_{0}+\frac{C_{1}-C_{0}}{2}\left[1+\operatorname{erf}\left(\frac{x}{2 \sqrt{D t}}\right)\right]
$$

$C_{0}$ is $\mathrm{Mg}$ concentration in coating layer, $C_{1}$ is $\mathrm{Mg}$ in $\mathrm{AZ31}$, and $D$ is diffusion coefficient of $\mathrm{Mg}$ in magnesium. The measured magnesium concentration and the profile calculated by eq. (1) were shown in Fig. 2(b). The profile calculated by eq. (1) corresponded to the measured values by quantitative analysis of EPMA. Thus it was concluded that the concentration gradient at the interface was caused by diffusion during the deposition coating process. This also means the adhesion between coating layer and substrate might be better than that by conventional deposition coating process that is carried on at room temperature.

On the other hand, although there were a lot of pin-holes through from interface to surface of coating layer, they were not harmful on the corrosion resistance. The authors reported
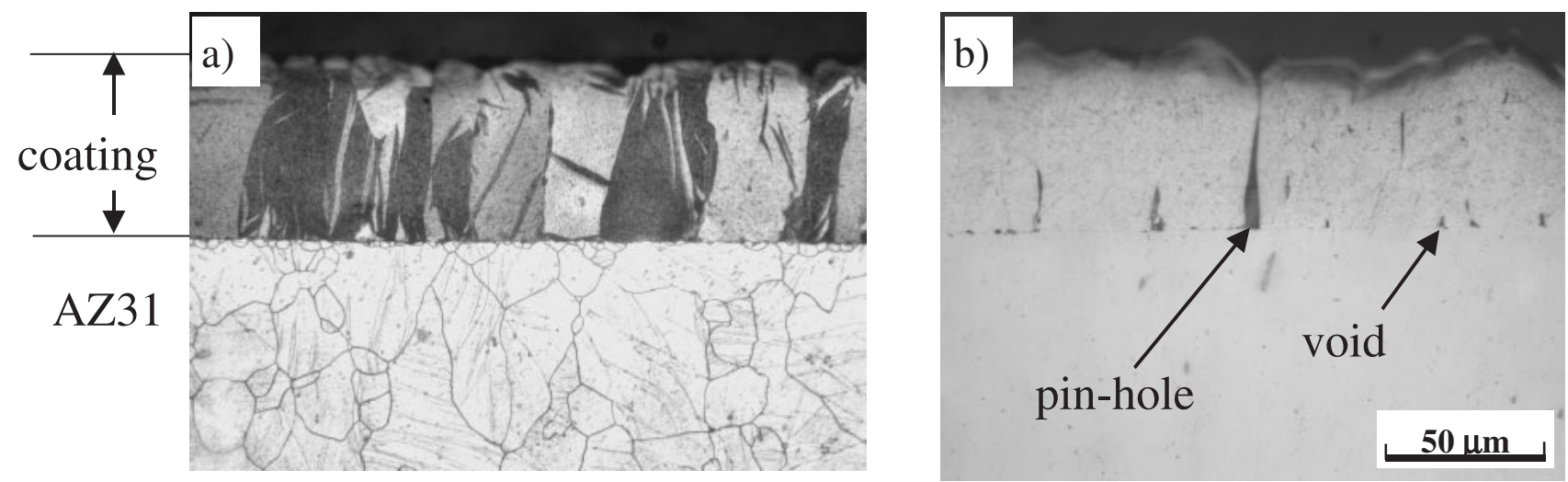

Fig. 1 Cross section of as-deposited sample; (a) etched, (b) non-etched. 

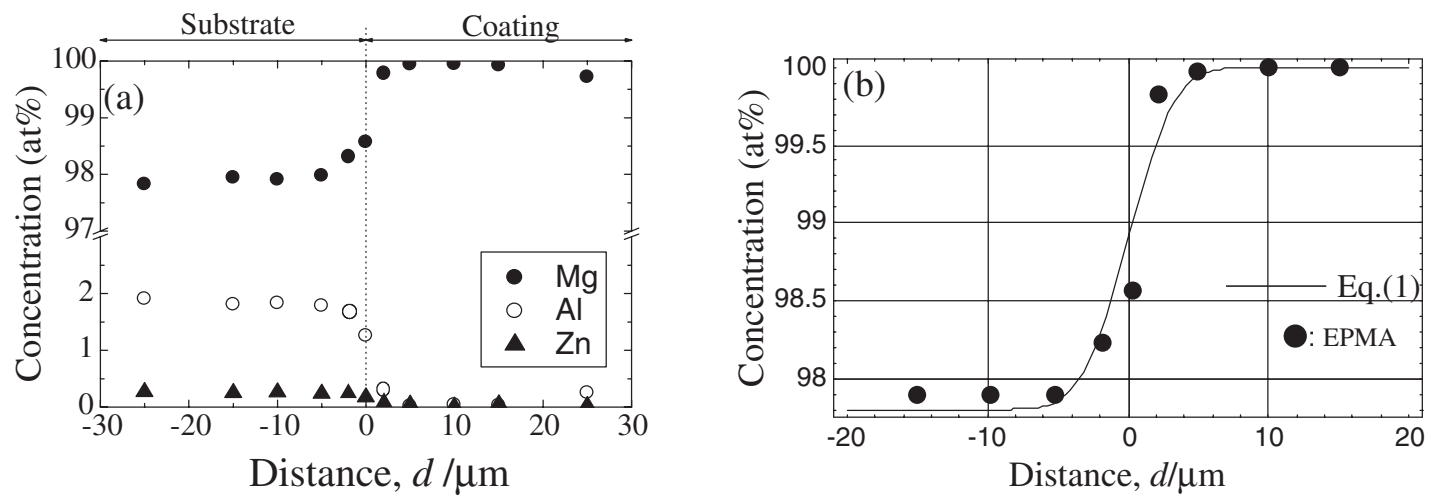

Fig. 2 Distribution of each element near interface for as-deposited sample; (a) quantitative analysis by EMPA, (b) profile of Mg calculated by eq. (1).

the improvement of corrosion resistance for the AZ31 by the vapor deposition process. ${ }^{11,12)}$ The self potential of AZ31 is higher than that of high purity magnesium. Therefore, if there is a pin-hole in the coating layer, the coating layer will plays as sacrificial anode and dissolve instead of the dissolution of substrate AZ31. Actually, as-deposited sample with pin-holes showed good corrosion resistance. ${ }^{11,12}$ However, influent solution through the pin-hole and voids will degrade the adhesion between coating layer and substrate. Therefore, it is necessary to eliminate pin-holes and voids considering application in severe environment for long term.

\subsection{Hot press and HIP}

The cross section after hot press and the void ratio are shown in Fig. 3 and Table 2, respectively. Thickness of coating layer decreased and twin structure were observed not
Table 2 Void ratio at the interface between coating and substrate.

\begin{tabular}{ccccc}
\hline & $\begin{array}{c}\text { Temperature } \\
(\mathrm{K})\end{array}$ & $\begin{array}{c}\text { Pressure } \\
(\mathrm{MPa})\end{array}$ & $\begin{array}{c}\text { Time } \\
(\mathrm{ks})\end{array}$ & $\begin{array}{c}\text { Void ratio } \\
(\%)\end{array}$ \\
\hline \multirow{2}{*}{$\begin{array}{c}\text { Hot } \\
\text { pressed }\end{array}$} & 523 & 100 & 3.6 & 6.0 \\
\cline { 2 - 5 } & 673 & 7 & 7.2 & 0.5 \\
\cline { 3 - 5 } & & & 3.6 & 0.7 \\
\hline As deposited & & & & 0.2 \\
\hline
\end{tabular}

only in substrate but also in coating layer due to the deformation. The void ratio decreased with increasing temperature, pressure and time. Eventually, the void ratio decreased to $0.2 \%$ by the hot press at $673 \mathrm{~K}$ for $7.2 \mathrm{ks}$ under

\section{a)}

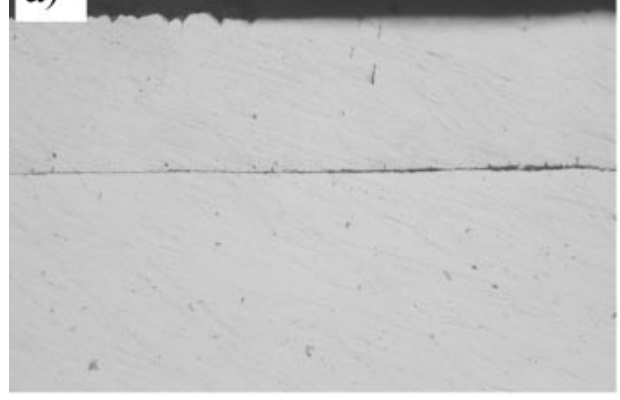

\section{c)}

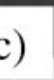

\section{b)}
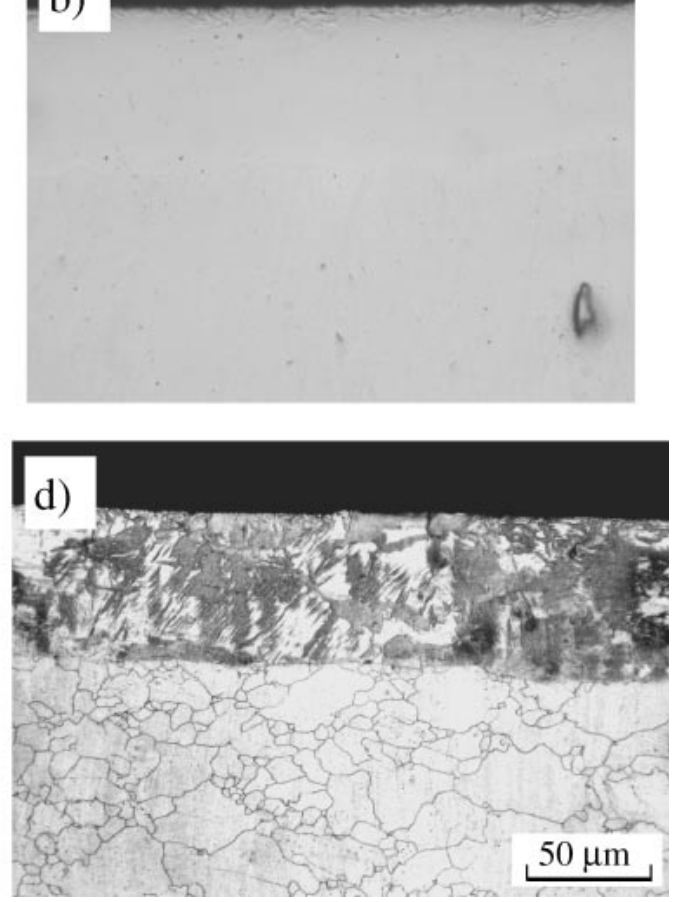

Fig. 3 Cross section of hot pressed samples; (a) $673 \mathrm{~K}, 0 \mathrm{MPa}, 7.2 \mathrm{ks}$, (b) $523 \mathrm{~K}, 7.2 \mathrm{ks}, 100 \mathrm{MPa}$, (c) $673 \mathrm{~K}, 7.2 \mathrm{ks}, 7 \mathrm{MPa}$, (d) $673 \mathrm{~K}$, $7.2 \mathrm{ks}, 7 \mathrm{MPa}$ (etched). 

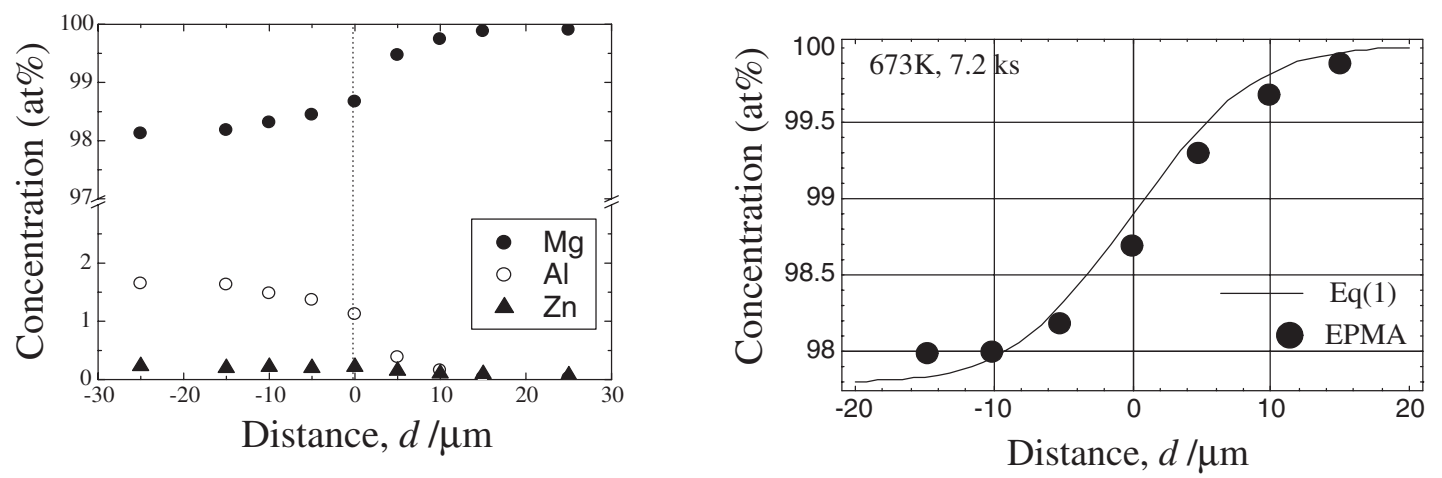

Fig. 4 Distribution of each element near interface after hot press for $7.2 \mathrm{ks}$ at $673 \mathrm{~K}$; (a) quantitative analysis by EMPA, (b) profile of Mg calculated by eq. (1).
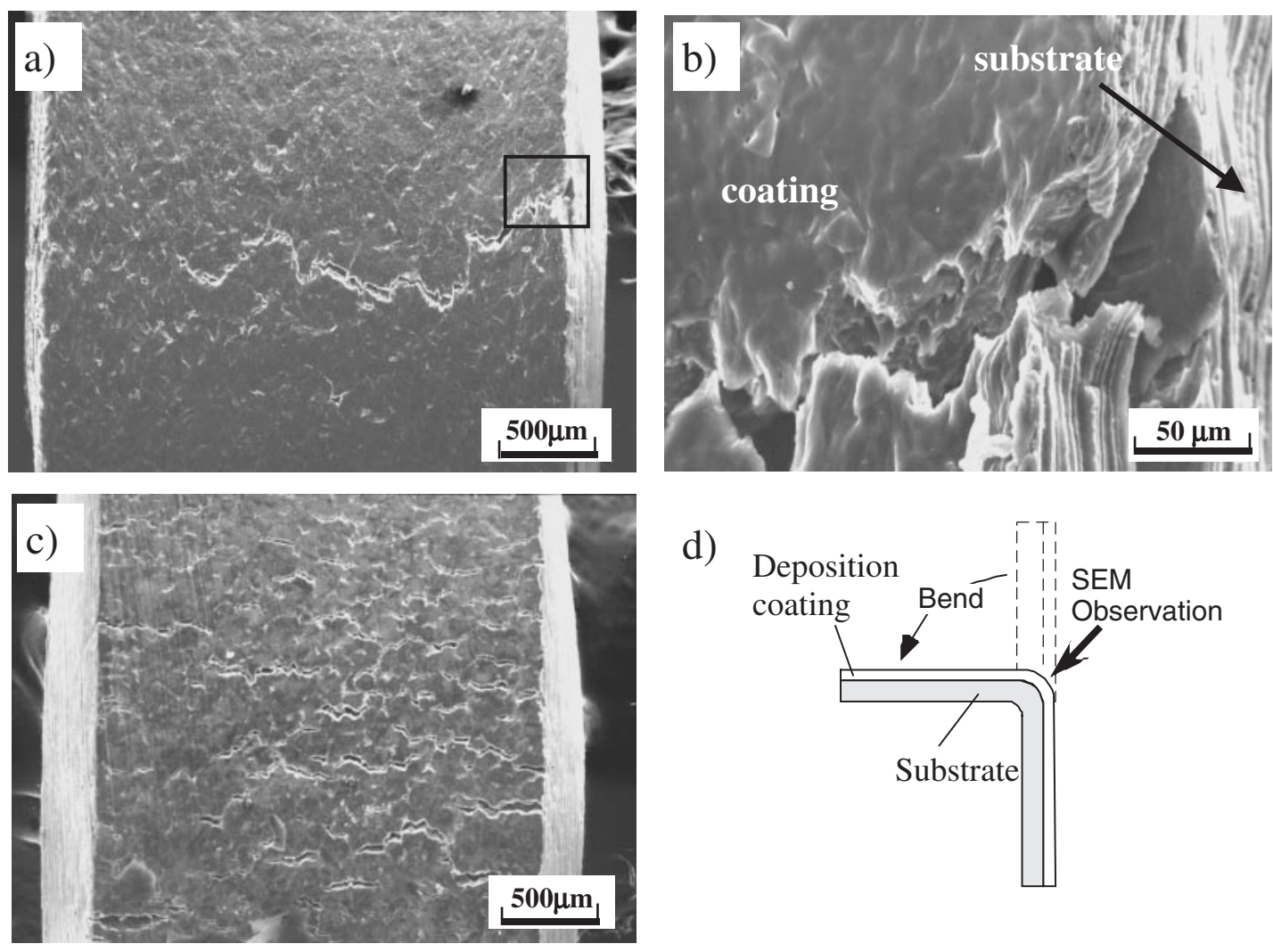

Fig. 5 SEM images of coated samples after bending test; (a) as-deposited, (b) higher magnification of (a), (c) hot pressed for 7.2 ks at $673 \mathrm{~K}$, (d) illustration of sample after bending test.

$7 \mathrm{MPa}$ and the pin-holes disappeared completely. The concentration profile of each element after the hot press at $673 \mathrm{~K}$ for $7.2 \mathrm{ks}$ is shown in Fig. 4. The interdiffusion at the interface was recognized obviously in comparison with as deposited specimen. Assuming the initial and boundary conditions are same to that in the case of Fig. 2, the concentration profile of $\mathrm{Mg}$ near the interface after the hot press is estimated in Fig. 4(b). The profile calculated by eq. (1) almost corresponded to the measured values. Thus, the voids at the interface were disappeared via diffusion bonding process. Although $\mathrm{Zn}$ and $\mathrm{Al}$ diffused into the coating layer via hot press, they did not reach the surface of the coating layer even in the optimum hot press condition that could diminish pin-holes and voids completely. Therefore, the optimum hot press condition to eliminate voids and pin-hole completely will not affect on the corrosion resistance of high purity magnesium coating.

The results of peel test are shown in Table 3. The adhesion strength between coating layer and substrate was $9.7 \mathrm{MPa}$ in as deposited specimen. The adhesion was considerably improved and the adhesion strength of hot pressed specimens were over $30 \mathrm{MPa}$. Since the strength of the joints by epoxy resin was smaller than the adhesion strength, the accurate adhesion strength could not be evaluated.

On the other hand, the improvement of adhesion was also shown in the case of bending test. Figure 5 shows the SEM images of surface of coated layers in the bending test specimens before and after hot press. The coating layer was peeled off the substrate in the as deposited specimen because of a lot of voids at the interface. Cracks were also observed 
Table 3 Adhesion strength between coating layer and substrate.

\begin{tabular}{ccc}
\hline \multicolumn{2}{c}{ Hot press condition } & $\begin{array}{c}\text { Tensile strength } \\
(\mathrm{MPa})\end{array}$ \\
\hline As deposited & & 9.7 \\
\hline $673 \mathrm{~K}, 7.0 \mathrm{MPa}$ & $3.6 \mathrm{ks}$ & $>30.4$ \\
\cline { 2 - 3 } & $7.2 \mathrm{ks}$ & $>31.3$ \\
\hline $523 \mathrm{~K}, 100 \mathrm{MPa}$ & $3.6 \mathrm{ks}$ & $>31.8$ \\
\cline { 2 - 3 } & $7.2 \mathrm{ks}$ & $>30.5$ \\
\hline
\end{tabular}

on the coating surface. Meanwhile, there was no peel off between coating layer and the substrate in the hot pressed specimen although a lot of cracks were observed on the surface of coating layer. Since the coating layer consisted of columnar grain as shown in Fig. 1 that grew up from the substrate, cracks propagated along the grain boundary in the bending test. Anyway, the adhesion was obviously improved by the hot press due to the decrease of voids at the interface.

It was clarified that the adhesion between coating layer and substrate could be improved by diffusion bonding. However, uni-axial pressure hot press is not sufficient for applications because it must be necessary to coat whole surface of actual product which has complicate shape. Then the HIP was carried out to solve the problem. The coated specimen was evacuated in aluminum can before HIP. The cross section of interface after HIP is shown in Fig. 6. Voids and pin-holes were almost disappeared by HIP. Therefore, both HIP and hot press could be applied for the improvement of adhesion between deposition coating and substrate.

\subsection{Corrosion resistance}

Figure 7 shows the corrosion resistance of AZ31 with and without the deposition coating, hot pressed specimen, the other magnesium alloys and high purity magnesium $(6 \mathrm{~N})$. The corrosion resistance of $99.9 \%(3 \mathrm{~N})$ magnesium which was used as evaporation source was poorest. AZ91 and high purity magnesium $(6 \mathrm{~N})$ had superior corrosion resistance. AZ31 with the coating also exhibited the superior corrosion resistance that was equal to AZ91 and $6 \mathrm{~N}$ high purity magnesium. It is difficult to know the accurate chemical composition of coating by EPMA due to its resolution. However, the results of immersion test showed that the

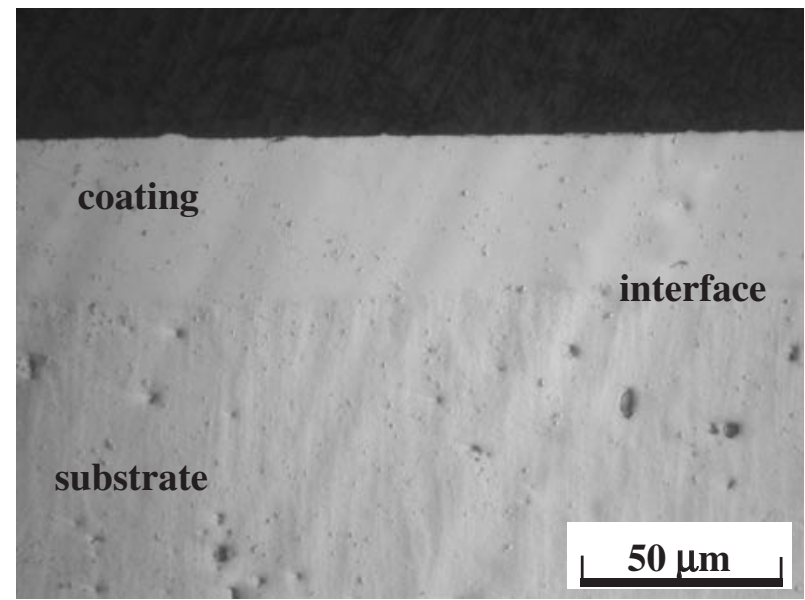

Fig. 6 Cross section after HIP for $7.2 \mathrm{ks}$ at $673 \mathrm{~K}$ under $100 \mathrm{MPa}$.

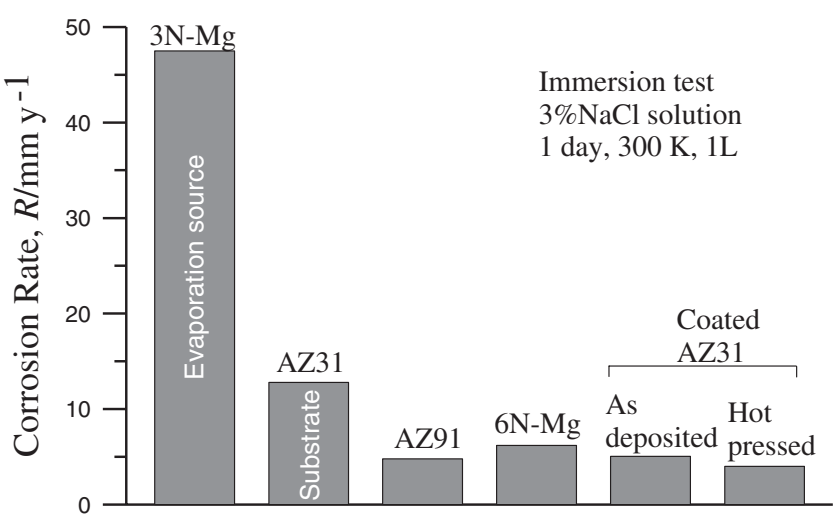

Fig. 7 Corrosion resistance of various magnesium alloys and coated AZ31.

chemical composition of coating layer might be equal to the $6 \mathrm{~N}$ high purity magnesium.

Cross cut test was carried out to estimate the adhesion and corrosion characteristics of hot pressed sample. Sample with scratches on coating surface was exposed in salt spray. Figure 8 shows the surface of hot pressed specimen after cross cut test. The scratches passed completely through to the AZ31 substrate. Any peel off could not be observed at the bottom of scratches. There were a lot of filiform corrosion on
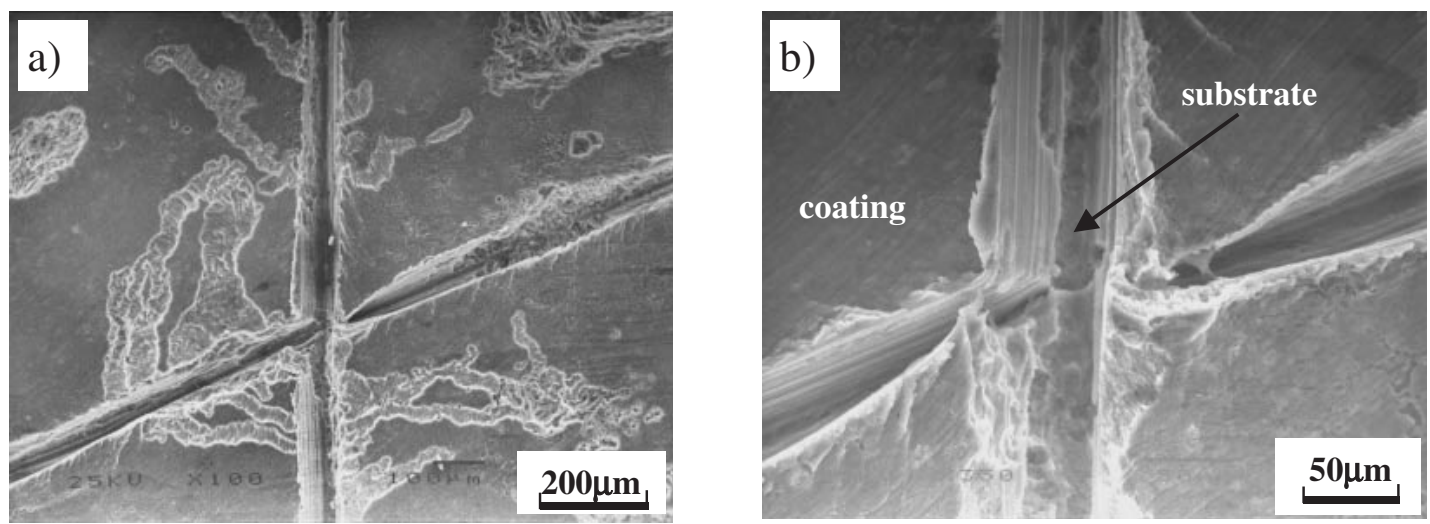

Fig. 8 Result of cross cut test for coated sample after hot press at $673 \mathrm{~K}$ for $7.2 \mathrm{ks}$; (a) surface of coating layer around scratches, (b) higher magnification of (a). 
the coating layer around scratches. These shows not only sound adhesion but also the effect of coating as sacrificial anode. Higher purity magnesium has lower self potential as described above. Therefore, coating layer dissolved preferentially into the solution instead of corrosion of substrate. As a result, the corrosion resistance of AZ31 magnesium alloys was improved by the deposition coating. Besides, corrosion resistance of hot pressed specimen was better than asdeposited one due to the disappearance of pin-holes.

\section{Conclusions}

Hot press and HIP were carried out to improve the adhesion and corrosion resistance of deposition coated AZ31 alloy with high purity magnesium. The following is a summary of the conclusions.

(1) There were voids and pin-holes at the interface between coating layer and substrate and in the coating layer, respectively, although corrosion resistance was improved by the deposition coating with high purity magnesium.

(2) The interdiffusion occurred during the deposition coating process at the interface. Although the interdiffusion proceeded during hot press, $\mathrm{Al}$ and $\mathrm{Zn}$ in the substrate did not reach the surface of coating layer even in the optimum condition of hot press.

(3) Voids and pin-holes could be disappeared by hot press and HIP. As a result, corrosion resistance and adhesion were improved.

(4) If the coating is broken locally, the high purity magnesium coating will work as sacrificial anode, and it will delay the corrosion of substrate.

\section{Acknowledgements}

The authors are grateful to Mr. Masaaki Tsukamoto of undergraduate student of Himeji Institute of Technology for his contribution. This work was supported by the Priority Group of Platform Science and Technology for Advanced Magnesium Alloys, Ministry of Education, Culture, Sports, Science and Technology, Japan.

\section{REFERENCES}

1) L. F. Spencer: Met. Finish 68 (1970) 32-35

2) L. F. Spencer: Met. Finish 68 (1970) 63-66.

3) L. F. Spencer: Met. Finish 68 (1970) 52-57.

4) R. Subramanian, S. Sicar and J. Mazumder: J. Mater. Sci. 26 (1990) 951-956.

5) P. L. Millerr, B. A. Shaw, R. G. Wendt and W. C. Moshier: Corrosion 49 (1993) 947-950.

6) J. D. Hanawalt, C. E. Nelson and J. A. Peloubet: Trans. AIME. 147 (1942) 273-299.

7) M. Takaya, K. Hashimoto and Y. Toda: J. J. I. L. M. 48 (1998) 352353.

8) E. F. Emley: Principles of Magnesium Technology, (Pergamon Press, Oxford, 1966) pp. 670-735.

9) S. Fukumoto, A. Yamamoto, M. Terasawa, T. Mitamura and H. Tsubakino: Mater. Trans. 42 (2001) 1232-1236.

10) I. Nakatsugawa, R. Martin and E. J. Knystautas: Corrosion 52 (1996) 921-926.

11) A. Yamamoto, A. Watanabe, K. Sugahara, H. Tsubakino and S. Fukumoto: Scr. Mater. 44 (2001) 1039-1042.

12) H. Tsubakino, A. Yamamoto, A. Watanabe, K. Sugahara and S. Fukumoto: Proc. The Fourth Pacific Rim International Conference on Advanced Materials and Processing (PRICM4), ed. by S. Hanada et al., (The Japan Institute of Metals, 2001) pp. 1263-1266.

13) P. G. Shewmon: Diffusion in Solid, (McGraw-Hill Book Company, Inc. New York, 1963) pp. 1-39. 